\title{
Finite control set model predictive control to balance DC-link capacitor voltage for T- Type NPC inverter of grid-connected photovoltaic systems
}

- Phan Quoc Dzung

- Nguyen Dinh Tuyen

- Nguyen Minh Nhat

Ho Chi Minh city University of Technology, VNU-HCM, Vietnam

(Manuscript Received on July 15, 2015, Manuscript Revised August 30, 2015)

\section{ABSTRACT}

This paper proposes the Finite control set Model Predictive Control (FCS-MPC) with delay compensation for three-phase threelevel T-Type NPC inverter (T-Type NPC) of grid-connected photovoltaic systems (PV). The proposed FCS-MPC controls the objectives: current tracking control, DC-link capacitor voltage balance, the reduction of switching frequency to ensure issues of the power quality and improve the efficiency of grid-connected of PV system. The cost

function of the proposed FCS-MPC uses the 27 possible switching states generated by $T$ Type NPC, the optimal switching state is selected in each sampling time that minimizes the cost function. The proposed FCS-MPC has also proposed the delay compensation with two-step prediction horizon at time $k+2$ to reduce the total harmonic distortion (THD) of the grid current. The proposed FCS-MPC is verified by using Matlab/Simulink.

Keywords: Finite control set Model predictive control, reduction of switching frequency, DClink Capacitor voltage balance, T-Type NPC, PV system.

\section{INTRODUCTION}

In the recent decades, photovoltaic system (PV system) quickly has been developed about the installed power, as well as the penetration into the electrical grid. Photovoltaic is the distributed generation, thus the stability when connecting the grid with the photovoltaic is a problem that worth to concern about at this moment. Due to the restrict of the two-level inverter is the output current with high THD distortion, the large size filters is chosen, however which causes some problems: reduction of the efficiency of PV system, high cost, bulky system [1], [2]. To solve these disadvantages, the three-phase three-level T-Type Neutral Point Clamp inverter (T-Type NPC), shown in Figure 1, is proposed, which has the advantages about the low THD of output current, high efficiency with switching frequency in $4 \mathrm{kHz}-30 \mathrm{kHz}$, small size, low investment cost [1], [2], [3].

The structure of a T-Type NPC includes two DC-link capacitors connected in series, thus the small voltage vectors and medium voltage vectors of T-Type NPC produce the voltage oscillations 
of the mid-point "O" of dc-link capacitor, making the unbalanced DC-link capacitors [5], [6]. The voltage oscillations of the mid-point of dc-link capacitor voltage causes the voltage stress on the capacitors and the semiconductor devices [4], [5]. Namely the failure in switching and the increase of THD of output current, due to the low-order harmonics of output voltage [3], [5], [6]. Pulse width modulation (PWM) is used to balance capacitor voltage with three-level NPC inverter [4]; three-level T-Type NPC [2], [3], [5]. However, the PWM algorithm has the complex calculation and is not easy to implement for the controlled objects that are nonlinearities and have many constraints [7], [8].

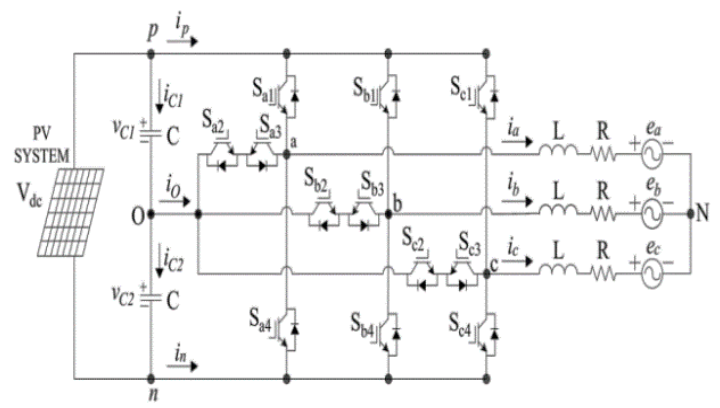

Figure 1. Three-level T-Type NPC inverter for threephase grid-connected of PV system

Model predictive control (MPC) bases on the good mathematical model of system to support the exact and complete the prediction about the future behaviors of system in control. In addition, the development of the microprocessor's speed allows calculating quickly the MPC [9], [10]. This makes MPC more and more popular in many fields of the power electronics. MPC have distinct advantages: simple, easy to implement, well control with the systems that are non-linear and have many constraints, fast responds with changing of the system, sustainable when compared to the classic control uses the proportional - integral controller (PI) and the PWM modulators [8], [9], [11], [12].
FCS-MPC has presented with the limited switching states of the converter for solving the optimization problem from a discrete model of the system [8], [10], [11], [14], [15]. Many researches with FCS-MPC have been presented for current tracking control and DC-link capacitor voltage balance [10], [13], [21], [14]; current tracking control and reduce switching frequency [7]. The FCS-MPC with delay compensation (two-step prediction horizon) has presented to reduce the THD of current [8], [11], [14], [15]. The FCSMPC with delay compensation will cause a big quantity of switching states due to two-step prediction horizon: $k+1, k+2$, for three-level $\mathrm{T}$ Type NPC, number of the switching states can correspond to $27^{2}=729$, the computation amount to select optimal switching state is massive.

This paper focuses on the control for the objectives of grid-connected of PV system: current tracking control, balancing dc-link capacitor voltage, the reduction of switching frequency by using the proposed FCS-MPC with delay compensation. In order to reduce the computation amount, this paper proposes that the values of current and dc-link capacitor voltages at time $k+1$, will be estimated based on the optimal switching state at time $\mathrm{k}-1$, then use these estimated values to predict the values at time $\mathrm{k}+2$. Therefore, the proposed FCS-MPC only chooses 27 switching states of T-Type NPC for two-step prediction horizon for the reduction of the computation amount in comparison [8], [15]. The optimal switching state is selected that minimizes the cost function of the proposed FCS-MPC. The change of weighting factor in the interrelationship between the objectives of cost function, will prove the flexibility of the proposed FCS-MPC for solving the problems of power quality and enhancing efficiency of grid-connected for PV system via the reduction of switching frequency.

2. MODEL OF T-TYPE NPC FOR GRIDCONNECTED OF PV SYSTEM

\subsection{Model of the system}

Trang6 
T-Type NPC for grid-connected of PV system using L-filter is illustrated in Figure 1, the dc-link voltage is assumed constant, we have the relation between voltage and current of gridconnected of PV system in (1) [11], [14], [17]:

$$
\begin{array}{r}
v_{a o}=L \frac{d i_{a}}{d t}+R i_{a}+e_{a}+v_{N o} \\
v_{b o}=L \frac{d i_{b}}{d t}+R i_{b}+e_{b}+v_{N o} \\
v_{c o}=L \frac{d i_{c}}{d t}+R i_{c}+e_{c}+v_{N o} \\
i_{a}, i_{b}, i_{c} \quad: \text { grid current } \\
e_{a}, e_{b}, e_{c} \quad: \text { grid voltage }
\end{array}
$$

$L, R$ : filter inductance and filter resistance of L-filter

$v_{a o}, v_{b o}, v_{c o}:$ output voltage of T-Type NPC

The voltage vector of T-Type NPC is defined:

Where, $a=e^{j 2 \pi / 3}$

$$
\begin{aligned}
& v=\frac{2}{3}\left(V_{a o}+a V_{b o}+a^{2} V_{c o}\right) \\
& a=e^{j 2 \pi / 3}
\end{aligned}
$$

Considering a constant dc-link voltage, and balanced capacitor voltages, the voltages generated by the T-Type NPC at the inverter terminals are obtained in (3) and Table 1 [14].

$$
V_{x o}=S_{x} \frac{V_{d c}}{2}
$$

Table 1. Switching state of T-Type NPC,

$$
\text { with } \mathrm{x}=\mathrm{a}, \mathrm{b}, \mathrm{c} \text { [1] }
$$

\begin{tabular}{|c|c|c|c|c|c|}
\hline \multirow{2}{*}{$\begin{array}{c}\text { Switching states } \\
\left(\mathbf{S}_{\mathbf{x}}\right)\end{array}$} & \multicolumn{4}{|c|}{ Switching status } & \begin{tabular}{c} 
Output \\
voltage \\
\cline { 2 - 6 }
\end{tabular} \\
\cline { 2 - 6 } & $\mathbf{S}_{\mathbf{x} 1}$ & $\mathbf{S}_{\mathbf{x} 2}$ & $\mathbf{S}_{\mathbf{x} 3}$ & $\mathbf{S}_{\mathbf{x} 4}$ & $\left(\mathbf{V}_{\mathbf{x} 0}\right)$ \\
\hline 1 & 1 & 1 & 0 & 0 & $\mathrm{~V}_{\mathrm{dc}} / 2$ \\
\hline 0 & 0 & 1 & 1 & 0 & 0 \\
\hline-1 & 0 & 0 & 1 & 1 & $-\mathrm{V}_{\mathrm{dc}} / 2$ \\
\hline
\end{tabular}

From (2), equation (1) is re-written:

$$
\begin{aligned}
& v=L \frac{d}{d t}\left(\frac{2}{3}\left(i_{a}+a i_{b}+a^{2} i_{c}\right)\right)+R\left(\frac{2}{3}\left(i_{a}+a i_{b}+a^{2} i_{c}\right)\right) \\
& +\frac{2}{3}\left(e_{a}+a e_{b}+a^{2} e_{c}\right)+\frac{2}{3}\left(v_{N o}+a v_{N o}+a^{2} v_{N o}\right)
\end{aligned}
$$

Grid current and grid voltage vector are defined [14], [17]:

$$
\begin{gathered}
i=\frac{2}{3}\left(i_{a}+a i_{b}+a^{2} i_{c}\right) \\
e=\frac{2}{3}\left(e_{a}+a e_{b}+a^{2} e_{c}\right)
\end{gathered}
$$

With,

$$
\frac{2}{3}\left(v_{N o}+a v_{N o}+a^{2} v_{N o}\right)=\frac{2}{3} v_{N o}\left(1+a+a^{2}\right)=0(7)
$$

From (4) (5) (6) (7), mathematical model of the grid-connected for PV system is re-written:

$$
v=L \frac{d i}{d t}+R i+e
$$

Equation (8) demonstrates the mathematical model of the grid-connected for PV system with T-Type NPC inverter. With the voltage vector is defined by (2), there are totally 19 separate voltage vectors for corresponding to 27 switching combinations of T-Type NPC as Figure 2.

\subsection{Grid-connected control for PV system}

Voltage oriented control (VOC) method is proposed to control grid-connected for PV system. According to [16], the instantaneous active and reactive powers in the rotating $d q$ frame injected into the grid by PV system are given in (9):

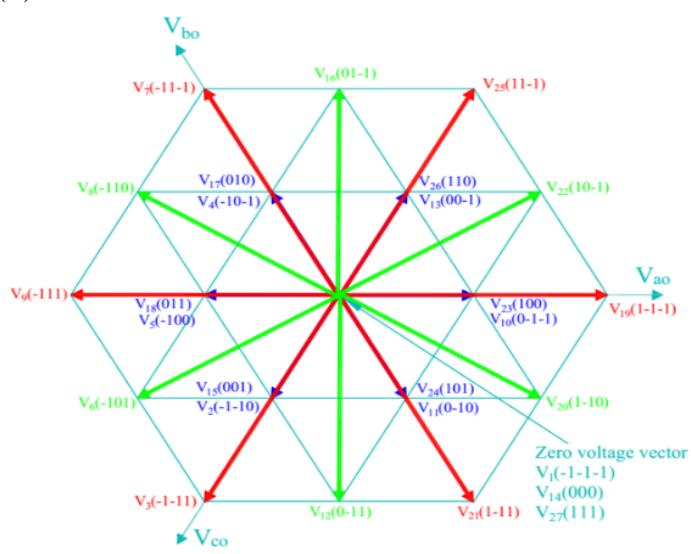

Figure 2. Voltage vectors and switching states can be generated by a T-Type NPC

$$
\begin{aligned}
& P=\frac{3}{2}\left(e_{d} i_{d}+e_{q} i_{q}\right) \\
& Q=\frac{3}{2}\left(e_{q} i_{d}-e_{d} i_{q}\right)
\end{aligned}
$$


$e_{d}, e_{q}$ : grid voltage in the rotating $d q$ frame

$i_{d}, i_{q}$ : grid current in the rotating $d q$ frame

Assuming that the $d$ axis is perfectly aligned with the grid voltage, thus $e_{q}=0$. The active power and reactive power are rewritten:

$$
\begin{gathered}
P=\frac{3}{2} e_{d} i_{d} \\
Q=-\frac{3}{2} e_{d} i_{q}
\end{gathered}
$$

From (10), we can independently control between active and reactive powers with $i_{d}$ and $i_{q}$ currents. We assume that: the dc-link voltage is constant, delivering symmetrical and balanced ac currents to the grid, so we can skip the calculation of the reference grid current $\left(i^{*}{ }_{q q}\right)$ [13]. In this paper, we only choose $i_{d q}^{*}$ as an external reference for implementing the proposed FCS-MPC, as shown in Figure 4.

\section{THE PROPOSED FCS-MPC}

\subsection{Finite control set model predictive control (FCS-MPC) with delay compensation}

FCS-MPC for the current tracking control presented in [11], [14]. $\mathrm{X}^{*}(\mathrm{k})$ represents the reference values of the desired control object, $\mathrm{x}(\mathrm{k})$ is the measured value at time $\mathrm{k}, \mathrm{x}(\mathrm{k}+2)$ is the predicted value for possible switching states of TType NPC inverter at time $\mathrm{k}+2$ (two-step prediction horizon). The error between $\mathrm{x}(\mathrm{k}+2)$ and $\mathrm{x}^{*}(\mathrm{k})$ is obtained to minimize the cost function and the switching state that minimizes the cost function will be chosen. FCS-MPC block diagram is illustrated in Figure 3 [9].

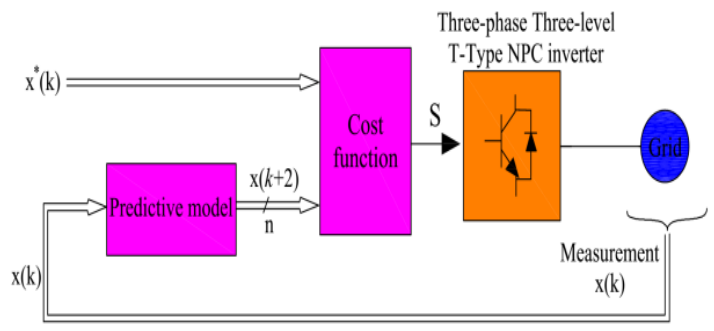

Figure 3. FCS-MPC block diagram
The proposed FCS-MPC for T-Type NPC of the grid-connected of PV system is illustrated in Figure 4. The proposed FCS-MPC for T-Type NPC of the grid-connected of PV system uses 27 switching states corresponding to 19 separate voltage vectors as Figure 2. The optimal switching state is selected that minimizes the cost function. The proposed FCS-MPC for grid-connected of PV system produces the optimized switching state directly to the T-Type NPC, without using the modulation techniques such as CB-PWM or Space Vector Modulation (SVM).

The proposed FCS-MPC for grid-connected of PV system has two main assumptions: keeping the stable DC-link voltage, symmetrical and balanced grid voltages, so we treat only $i^{*}{ }_{d q}(k)$ for controlling the grid-connected of PV system, not operating in islanded case with grid systems. From Figure 4, grid voltage and grid current are measured at time $k$, which are used for predicting the grid current at time $k+2$ and the predicted grid current shows in stationary $\alpha \beta$ frame. The reference grid current in the $d q$ frame have to show in stationary $\alpha \beta$ frame for implementing the proposed FCS-MPC, so we use Phase-LockedLoop block (PLL) to synchronize the phase angle $(\theta)$ between the grid system and the PV systems [16]. We use Park and Clark transformations for the conversion between the $a b c, \alpha \beta, d q$ frames with phase angle $(\theta)$ calculated by PLL blocks. The cost-function of the proposed FCS-MPC produces the optimal switching state based on the reference grid current and the predicted grid current, or other controlled objectives. In this paper, $\mathrm{x}(\mathrm{k})$ presents for the desired control objectives: grid current, DC-link voltage, switching frequency. 


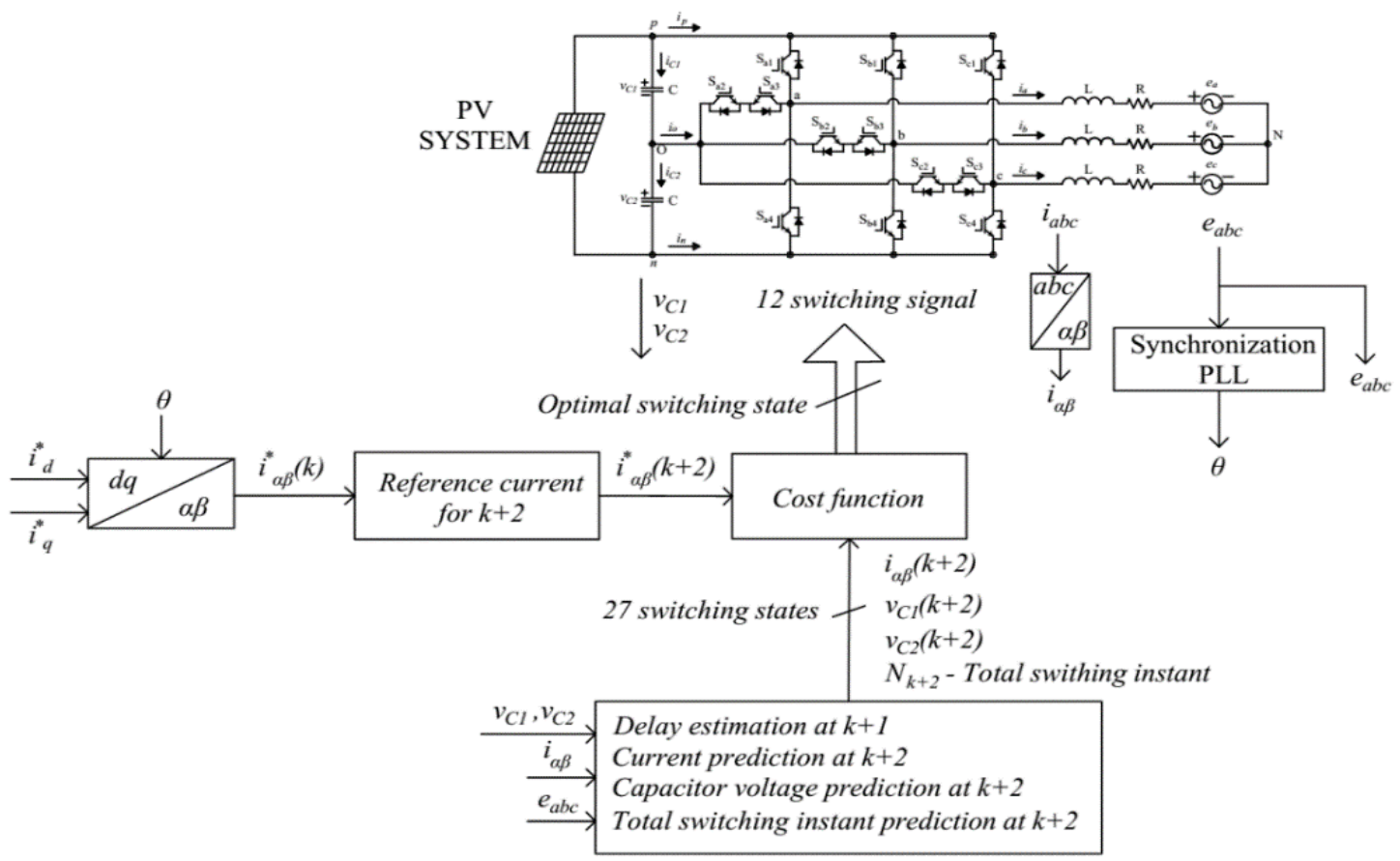

Figure 4. The proposed FCS-MPC applies for T-Type NPC of grid-connected of PV System

\subsection{Current tracking control}

Applying a sampling period $T_{s}$, the derivative of grid current in (8) will be approximated by Euler forward method [14], [17], as follows:

$$
\frac{d i}{d t} \approx \frac{i(k+1)-\mathrm{i}(\mathrm{k})}{T_{s}}
$$

$i(k+1)$ is the predicted grid current at time $k+1, i(k)$ is the value of grid current measured at time $k$. From (8), (11) and grid voltage $e(k)$ measured at time $k$, the equation of the predicted grid current at time $k+1$ is rewritten:

$$
i^{p}(k+1)=\left(1-\frac{R T_{s}}{L}\right) i(k)+\frac{T_{s}}{L}(v(k)-e(k))
$$

$v(k)$ is voltage vector of inverter and depending on the switching states of T-Type NPC inverter as (2) and (3), so the predicted grid current $i(k+1)$ at each time will vary and depends on the switching states.
According to the proposed FCS-MPC with delay compensation, the grid current at $k+1$ time is estimated based on the grid current and voltage current measured at time $k$, thus the estimated grid current has the value as (12), meaning $i^{p}(k+1)=$ $i^{\wedge}(k+1)$, with $i^{\wedge}(k+1)$ is the estimated value at time $k+1$ and $v(k)$ is the optimal voltage vector which was calculated at time $k-1$. The estimation value $i^{\wedge}(k+1)$ will be used for predicting the grid current $i^{p}(k+2)$ at time $k+2$, considering all possible switching states of T-Type NPC [14]. The prediction of grid current at time $(k+2)$ is defined: $i^{p}(k+2)=\left(1-\frac{R T_{s}}{L}\right) \hat{i}(k+1)+\frac{T_{s}}{L}(v(k+1)-e(k+1))(13)$
$v(k+1)$ is voltage vector of T-Type NPC for considering all possible switching states generated by the inverter. $e(k+1)$ is the grid voltage at time $k+1$. The value $e(k+1)$ can be determined by Lagrange extrapolation formula as follows [14]:

$$
e(k+1)=3 e(k)-3 e(k-1)+e(\mathrm{k}-2)
$$


For a small enough $T_{s}$, we can approximate $e(k+1) \approx e(k)$, equation (13) is rewritten:

$$
i^{p}(k+2)=\left(1-\frac{R T_{s}}{L}\right) \hat{i}(k+1)+\frac{T_{s}}{L}(v(k+1)-e(k))
$$

From equation (15) shows that the different switching states of T-Type NPC inverter will produce the different values of predicted grid current at time $\mathrm{k}+2$. The cost function for current tracking control is defined with the predicted grid current and the reference grid current at time $k+2$, gives in (16):

$$
\begin{gathered}
g_{1}=\left(i_{\alpha}^{*}(k+2)-i_{\alpha}^{p}(k+2)\right)^{2}+\left(i_{\beta}^{*}(k+2)-i_{\beta}^{p}(k+2)\right)^{2}(16) \\
i^{p}(k+2)=i_{\alpha}^{p}(k+2)+j i_{\beta}^{p}(k+2) \\
i^{*}(k+2)=i_{\alpha}^{*}(k+2)+j i_{\beta}^{*}(k+2)
\end{gathered}
$$

$i^{p}{ }_{\alpha}(k+2), i^{p}{ }_{\beta}(k+2)$ of the predicted grid current and $i_{\alpha}^{*}(k+2), i_{\beta}^{*}(k+2)$ of the reference grid current show in $\alpha \beta$ frame at time $k+2$.

The $i^{*}(k+2)$ at time $k+2$ can be determined by Lagrange extrapolation formula as follows [14]:

$$
i^{*}(k+2)=6 i^{*}(k)-8 i^{*}(k-1)+3 i^{*}(\mathrm{k}-2)
$$

For a small enough $T_{s}$, we can approximate $i^{*}(k+2) \approx i^{*}(k)$ [14], [17]. The cost function for current tracking control is rewritten:

$$
g_{1}=\left(i_{\alpha}^{*}(k)-i_{\alpha}^{p}(k+2)\right)^{2}+\left(i_{\beta}^{*}(k)-i_{\beta}^{p}(k+2)\right)^{2}(20)
$$

\subsection{Reduction of switching frequency}

The switching frequency for MPC is limited to half the sampling frequency $\left(f_{s}\right)$ [14], [17]. The switching frequency is the average switching frequency value of power semiconductors of inverter. Switching frequency for FCS-MPC for T-Type NPC with 12 power semiconductors (IGBTs) is calculated [11], [17]:

$$
f_{s w}=\frac{N}{12 * t}
$$

$N$ : the total switching instants of 12 IGBTs during period of $t$

$t \quad$ : time of simulation or experiment

The total switching instants $N$ should be decreased to reduce the switching frequency. Comparing the 27 switching states of T-Type NPC inverter with optimum switching state at time $k-1$ to thereby calculate switching instants for each switching state. The cost function for reducing the switching frequency is defined:

$$
g_{2}=\lambda_{s \mathrm{w}} \cdot N_{k+2}
$$

$\lambda_{s w}$ : weighting factor of the reduction of switching frequency

$N_{k+2}$ : the total switching instants is calculated by the change between of each expected switching state of the 27 possible switching states generated by T-Type NPC with optimal switching state was chosen at time $k-1$.

\subsection{Balancing DC-link capacitor voltages}

Assuming the DC-link capacitor voltage is constant. From Figure 1, the prediction for the voltage of each capacitor at the time $k+1$ is [14]:

$$
\begin{aligned}
& v_{C 1}(k+1)=\mathrm{v}_{\mathrm{C} 1}(\mathrm{k})+\frac{T_{s}}{C} i_{C 1}(k)=\mathrm{v}_{\mathrm{Cl}}(\mathrm{k})+\frac{T_{s}}{2 C} i_{o}(k) \\
& v_{C 2}(k+1)=\mathrm{v}_{\mathrm{C} 2}(\mathrm{k})+\frac{T_{s}}{C} i_{C 2}(k)=\mathrm{v}_{\mathrm{C} 2}(\mathrm{k})-\frac{T_{s}}{2 C} i_{o}(k)
\end{aligned}
$$

$v_{C 1}, v_{C 2} \quad$ : DC-link capacitor voltage

$C$ : capacitance of each DC-link capacitor

$i_{o}$ : current at the mid-point of dc-link capacitor "O"

The current at the mid-point of dc-link capacitor "O" can be defined from currents $i_{a}, i_{b}$, $i_{c}$ on each phase at the current time and switching state depended function $S_{x o}$, with switching state $S_{\mathrm{x}}$ in Table 1 [14]:

$$
\begin{aligned}
& i_{o}(k)=S_{a o}(k) i_{a}(k)+S_{b o}(k) i_{b}(k)+S_{c o}(k) i_{c}(k) \\
& S_{x o}=1 \text { if } S_{x}=0 ; S_{x o}=0 \text { if } S_{x}=1 \text { or }-1 ; \\
& \quad \text { with } x=a, b, c
\end{aligned}
$$

The proposed FCS-MPC will delay 01 sampling period $\left(T_{s}\right)$, thus we will predict the future value $k+2$ based on the estimated value at the time $k+1$. DC-link capacitor voltage is predicted at time $k+2[14]$ :

$$
\begin{aligned}
& v_{C 1}(k+2)=v_{C 1}(k+1)+\frac{T_{s}}{C} i_{C 1}(k+1)=v_{C 1}(k+1)+\frac{T_{s}}{2 C} i_{o}(k+1) \\
& v_{C 2}(k+2)=v_{C 2}(k+1)+\frac{T_{s}}{C} i_{C 2}(k+1)=v_{C 2}(k+1)-\frac{T_{s}}{2 C} i_{o}(k+1)
\end{aligned}
$$


$v(k+1)$ is the voltage vector corresponding to 27 the possible switching states in the proposed FCS-MPC. The current at the mid-point of dc-link capacitor "O" at time $k+1$ is written:

$i_{o}(k+1)=S_{o}(k+1) i_{a}(k+1)+S_{o}(k+1) i_{b}(k+1)+S_{o}(k+1) i_{c}(k+1)(27)$

$i_{o}(k+1)$ is defined based on the estimated grid current $i(k+1)$ at the time $\mathrm{k}+1$, and $S_{a o}(k+1)$, $S_{b o}(k+1), \quad S_{c o}(k+1)$ correspond to all of the switching states of inverter as (25).

The differentiation of DC-link capacitor voltage is defined:

$$
\Delta V_{D C}(k+2)=v_{C 1}(\mathrm{k}+2)-\mathrm{V}_{\mathrm{C} 2}(\mathrm{k}+2)
$$

From the (26) and (28), we have:

$\Delta V_{D C}(k+2)=v_{C 1}(\mathrm{k}+1)-\mathrm{V}_{\mathrm{C} 2}(\mathrm{k}+1)+\frac{T_{s}}{C} i_{o}(k+1)$

Cost function for DC-link capacitor voltage balance is defined in (34):

$$
g_{3}=\lambda_{D C}\left(\Delta V_{D C}(k+2)\right)^{2}
$$

$\lambda_{D C}$ : weighting factor of capacitor voltage balance.

\subsection{Cost function of the proposed FCS - MPC}

From (20), (22), (30), the proposed FCS MPC for controlling many objectives: current tracking control, balancing the DC-link capacitor voltage, reduction of switching frequency with the cost function is defined:

$g=g_{1}+g_{2}+g_{3}$

$=\left(i_{\alpha}^{*}(k)-i_{\alpha}^{p}(k+2)\right)^{2}+\left(i_{\beta}^{*}(k)-i_{\beta}^{p}(k+2)\right)^{2}+\lambda_{D C}\left(\Delta V_{D C}(k+2)\right)^{2}+\lambda_{S w} N_{k+2}$

Depending on the priority of the controlled objectives, we can adjust the weighting factors $\left(\lambda_{D C}, \lambda_{s w}\right)$ represented for objectives to obtain the optimal switching state. Some guidelines on choosing weighting factor for the desired objectives may refer in [18].

The optimal switching state is selected by the minimized of cost function $\mathrm{g}$.

\section{SIMULATION RESULTS}

The specifications for the system in Figure 1 are: $\mathrm{R}=0.5 \Omega ; \mathrm{L}=5 \mathrm{mH} ; \quad \mathrm{V}_{\text {grid }}=220 \mathrm{~V} ; \quad \mathrm{V}_{\mathrm{dc}}$ - link $=\mathrm{V}_{\mathrm{dc}}=700 \mathrm{~V} ; \mathrm{f}_{\text {grid }}=50 \mathrm{~Hz} ; \mathrm{C}_{1}=\mathrm{C}_{2}=5 \mathrm{mF}$. To demonstrate the flexibility for controlling gridconnected of PV systems, the reference grid current of $d$-axis of the rotating $d q$ frame will have the different values at different times, and the reference grid current of $q$-axis with $\mathrm{i}_{\text {qref }}=0 \mathrm{~A}$; sample time $\mathrm{T}_{\mathrm{s}}=25 \mu \mathrm{s}$ with sampling frequency $\mathrm{f}_{\mathrm{s}}=1 / \mathrm{T}_{\mathrm{s}}=40 \mathrm{kHz}$ applies the proposed FCS-MPC:

$$
\begin{aligned}
& +\mathrm{t}=0 \mathrm{~s}-0.2 \mathrm{~s} ; \mathrm{i}_{\text {dref }}=4 \mathrm{~A}, \mathrm{i}_{\text {qref }}=0 \mathrm{~A} \\
& +\mathrm{t}=0.2 \mathrm{~s}-0.3 \mathrm{~s} ; \mathrm{i}_{\text {dref }}=10 \mathrm{~A}, \mathrm{i}_{\text {qref }}=0 \mathrm{~A} \\
& +\mathrm{t}=0.3 \mathrm{~s}-0.5 \mathrm{~s} ; \mathrm{i}_{\text {dref }}=6 \mathrm{~A}, \mathrm{i}_{\text {qref }}=0 \mathrm{~A}
\end{aligned}
$$

In this paper, weighting factor of the capacitor voltage balance with $\lambda \mathrm{DC}=8$ and weighting factor of the reduction of switching frequency with $\lambda_{\mathrm{sw}}=0.1$ và $\lambda_{\mathrm{sw}}=1.5$ are used to compare the responses of the grid-connected of PV system.

The proposed FCS-MPC for T-Type NPC of grid-connected of PV system provides the fast response to the power change of system with decoupled control active power $(P)$ and reactive power $(Q)$ in the rotating $d q$ frame via the current tracking control. At the time $\mathrm{t}=0.2 \mathrm{~s}$, the reference grid current is ordered to change from $i_{\text {dref }}=4 \mathrm{~A}$ to $i_{\text {dref }}=10 \mathrm{~A}$, and at the time $t=0.3 \mathrm{~s}$, the reference grid current is ordered to change from $i_{\text {dref }}=10 \mathrm{~A}$ to $i_{\text {dref }}=6 \mathrm{~A}$, system's response is fast, as shown in Figure 5 and Figure 6. Corresponding to the change of power supply, the grid current in $a b c$ frame in Figure 8, at the time of $\mathrm{t}=0.2 \mathrm{~s}$ and $\mathrm{t}=$ $0.3 \mathrm{~s}$, has a fast response and a good current tracking control.

For the proposed FCS - MPC, the reduction of switching frequency shows the interrelation between the weighting factor of the reduction of switching frequency and weighting factor of capacitor voltage balance. The switching frequency of PWM is constant. FCS-MPC chooses the optimal voltage vector, minimizes the cost function, hence there is a independence between sampling frequency and switching 
frequency [7], [14]. We can see that the switching frequency depends on the weighting factors $\lambda_{s w}$ in the cost function. With the same capacitor balance weighting factor $\lambda_{\mathrm{DC}}=8$, and $\lambda_{\mathrm{sw}}=1.5$ produces the THD of grid current is higher than implemented by $\lambda_{\mathrm{DC}}=8, \lambda_{\mathrm{sw}}=0.1$, shown in Figure 5(a) and Figure 5(b).
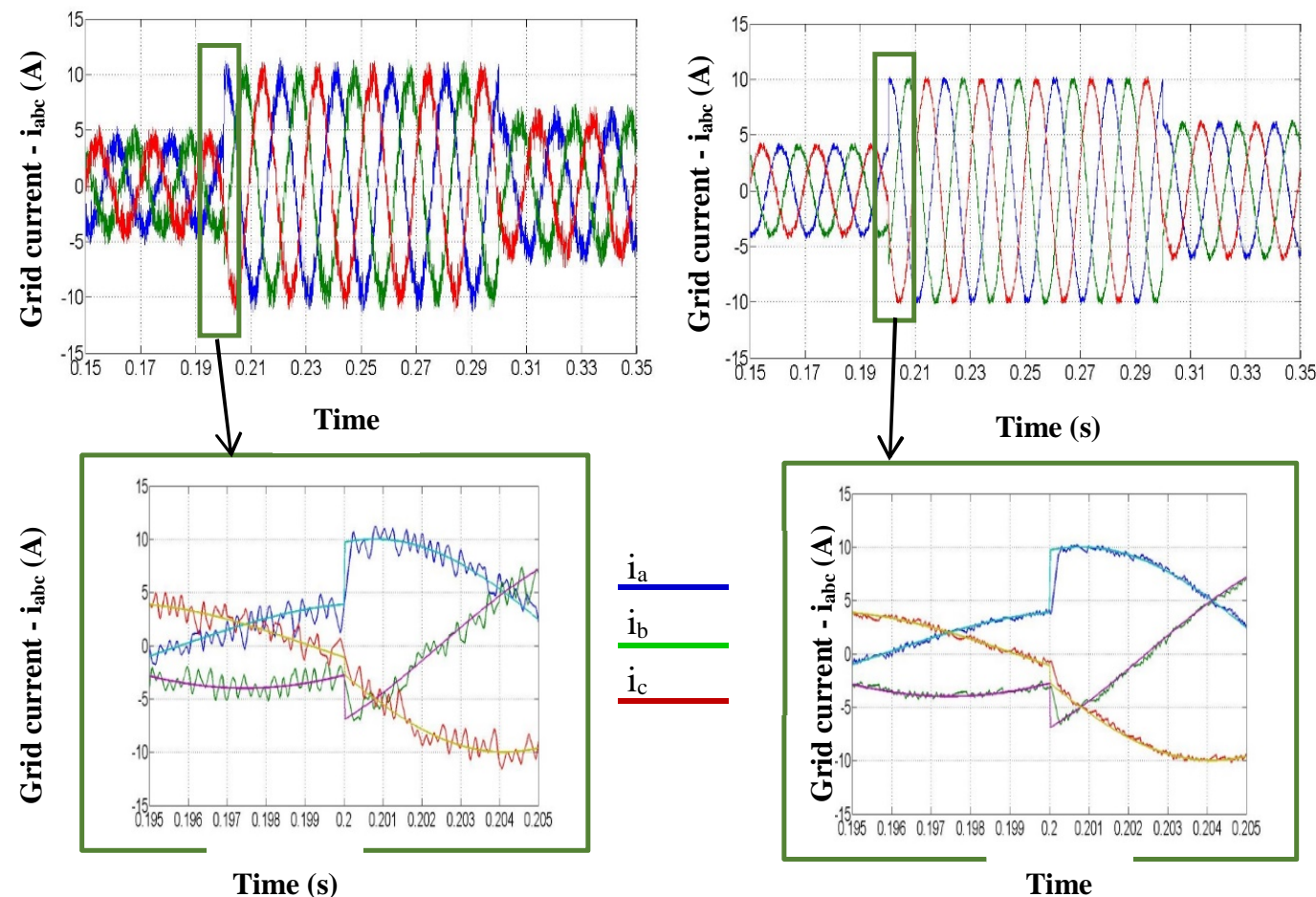

Time (s)

\section{Time}
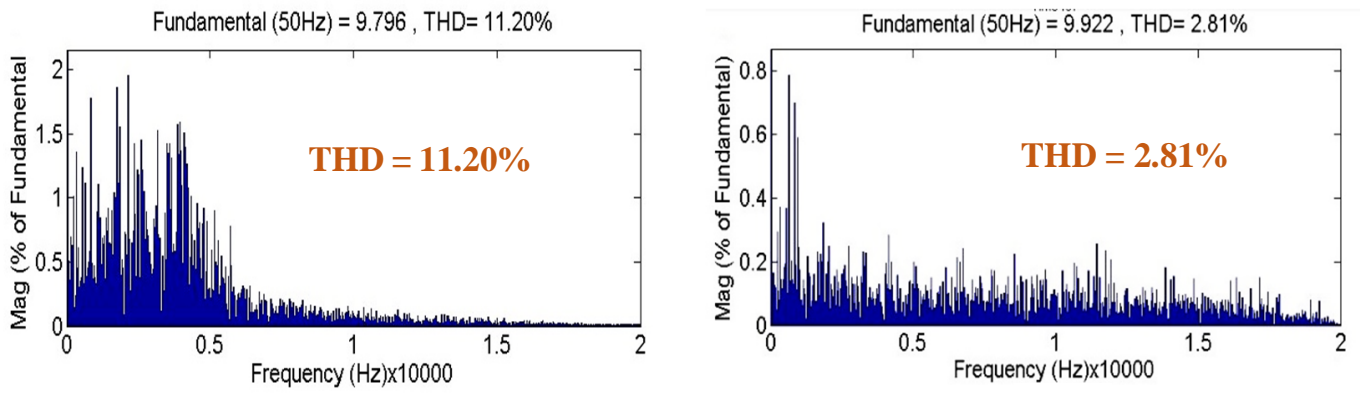

(a)

Figure 5. Waveform and THD of grid current in abc frame: (a) $\lambda_{\mathrm{DC}}=8, \lambda_{\mathrm{sw}}=1.5$; (b) $\lambda_{\mathrm{DC}}=8, \lambda_{\mathrm{sw}}=0.1$ 

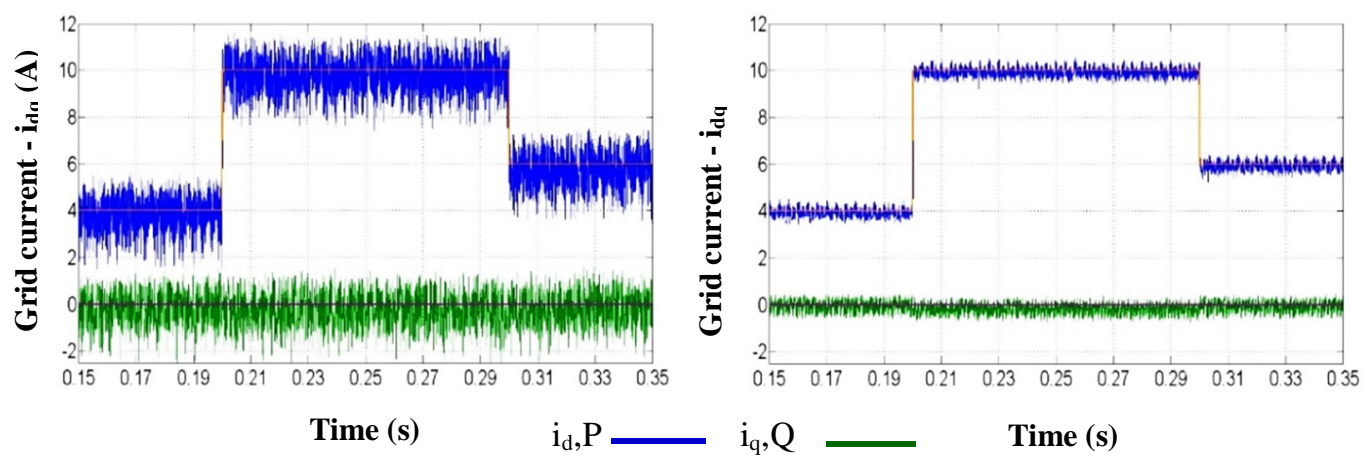

Time (s)

$\mathrm{i}_{\mathrm{d}}, \mathrm{P}$

(b)

Figure 6. Waveform of grid current in the rotating $d q$ frame: (a) $\lambda_{\mathrm{DC}}=8, \lambda_{\mathrm{sw}}=1.5$; (b) $\lambda_{\mathrm{DC}}=8, \lambda_{\mathrm{sw}}=0.1$
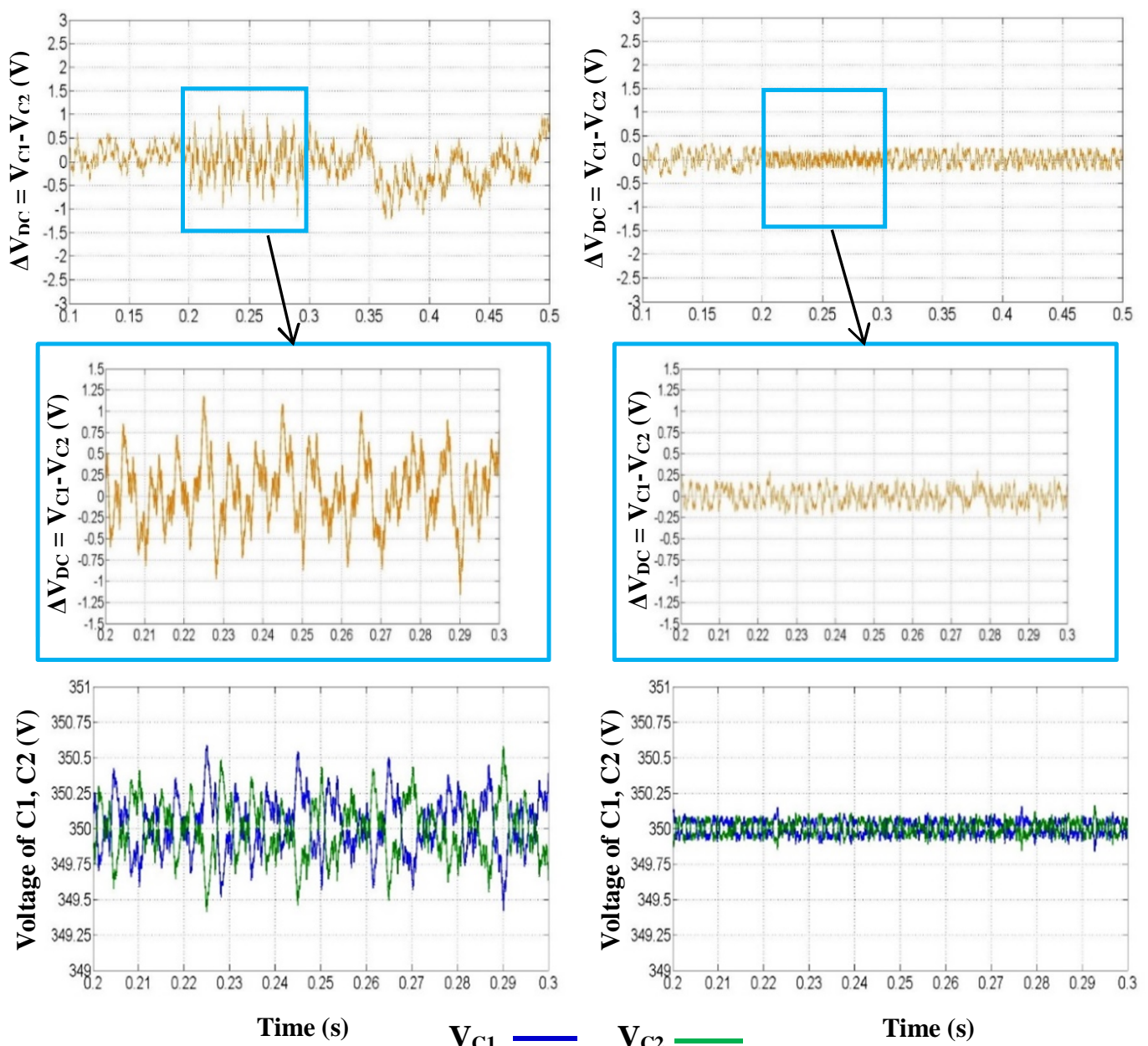

(a)

(b)

Figure 7. The differentiation of DC-link capacitor voltage $\Delta \mathrm{V}_{\mathrm{DC}}$, capacitor voltage of $\mathrm{C} 1$ and C2 capacitor: (a) $\lambda_{\mathrm{DC}}=8, \lambda_{\mathrm{sw}}=1.5 ;$ (b) $\lambda_{\mathrm{DC}}=8, \lambda_{\mathrm{sw}}=0.1$ 


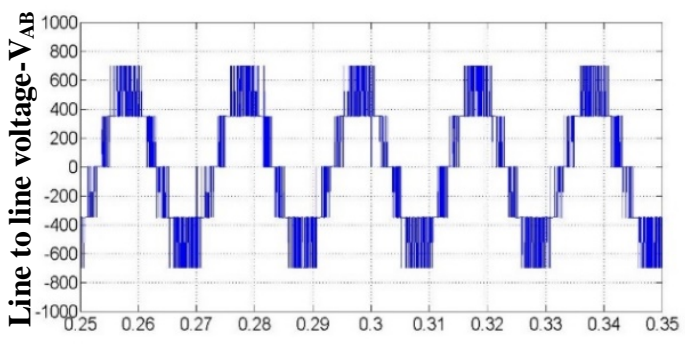

Time (s)

(a)

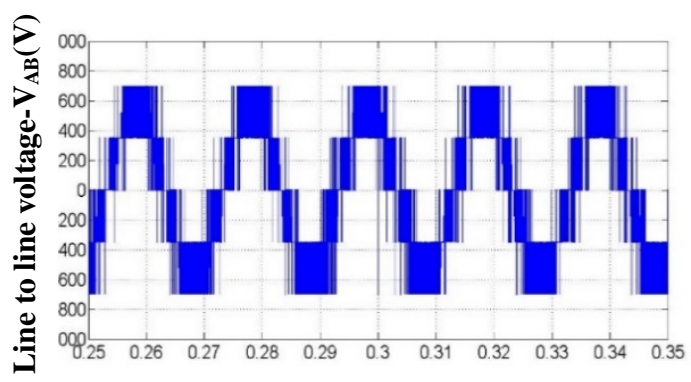

Time (s)

(b)

Figure 8. Wave form of output voltage of $T$-Type NPC inveter $-V_{A B}$ (Line to line voltage $-V_{A B}$ ) and $V_{A N}$ (Voltage of phase A): (a) $\lambda_{\mathrm{DC}}=8, \lambda_{\mathrm{sw}}=1.5$; (b) $\lambda_{\mathrm{DC}}=8, \lambda_{\mathrm{sw}}=0.1$

The increasing weighting factor of the reduction of switching frequency will make the reduction of switching frequency and the increase of THD of grid current, as shown in Figure 5, Figure 9 and Table 2.

Similarly, the increasing weighting factor of the reduction of switching frequency, the priority of DC-link capacitor voltage balance will decrease, so the voltage oscillations of the midpoint of dc-link capacitor "O" will increase, as shown in Table 2. With $\lambda_{\mathrm{DC}}=8$ and $\lambda_{\mathrm{sw}}=1.5$ produces $\Delta \mathrm{V}_{\mathrm{DC}}=1.2 \mathrm{~V}$, as shown in Figure 7(a); with $\lambda_{\mathrm{DC}}=8$ and $\lambda_{\mathrm{sw}}=0.1$ only produces $\Delta \mathrm{V}_{\mathrm{DC}}=$ $0.27 \mathrm{~V}$ as shown in Figure 7(b). From Table 2 and Figure 9 (using Microsoft Excel to sketch), with the $\lambda_{\mathrm{DC}}=8$, the increasing weighting factor of reduction of switching frequency corresponds to reduce the switching frequency and increase the voltage oscillations of the mid-point of dc-link capacitor, and the correlation between the voltage oscillations of the mid-point of dc-link capacitor and weighting factor of reduction of switching frequency is almost linear. Waveforms of line-toline voltage of T-Type NPC is illustrated in Figure 8 , which comply with wave forms of output voltage of T-Type NPC.
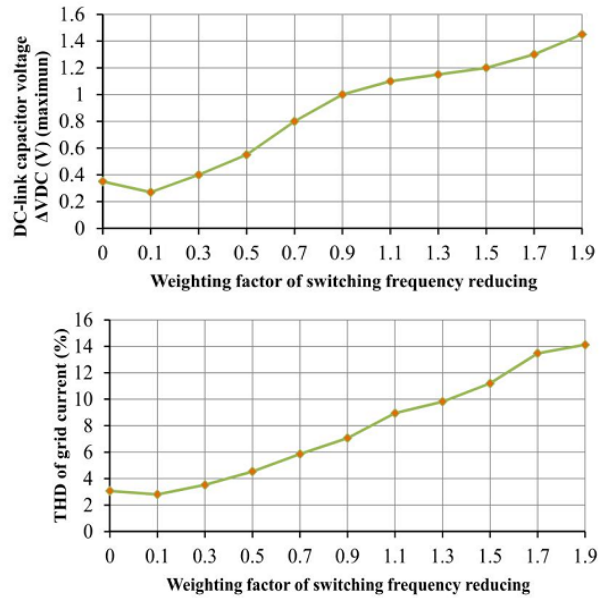

Figure 9. The effects of weighting factor of the reduction switching frequency to: The DC-link capacitor voltage balance and THD of grid current

Table 2 shows the independence between the sampling frequency and the switching frequency via the control of the interrelation between objectives: grid current, DC-link capacitor voltage, switching frequency by the cost function of the proposed FCS-MPC. With $\lambda_{\mathrm{DC}}=8, \lambda_{\mathrm{sw}}=$ 0,1 , the THD of grid current is only $2,81 \%$, the DC-link capacitor voltage is the best value with $\Delta \mathrm{V}_{\mathrm{DC}}=0,27 \mathrm{~V}$ and the switching frequency is $4.99 \mathrm{kHz}$, complying with the switching frequency for T-Type NPC with high efficiency 
[1]. The proposed FCS-MPC provides the THD of grid current to meet the requirements for grid connected of PV system as IEEE 1547 and IEC 61727.

Table 2. The quantitative of the desired objectives, with $\mathrm{T}_{\mathrm{s}}=25 \mu \mathrm{s}, \mathrm{f}_{\mathrm{s}}=40 \mathrm{kHz}$

\begin{tabular}{|c|c|c|c|c|}
\hline $\begin{array}{c}\text { Weighting } \\
\text { factor of } \\
\text { the } \lambda_{D C}\end{array}$ & $\begin{array}{c}\text { Weighting } \\
\text { factor of } \\
\lambda_{s w}\end{array}$ & $\begin{array}{c}\text { Switching } \\
\text { frequency } \\
\mathbf{f}_{\mathrm{sw}}(\mathbf{k H z})\end{array}$ & $\begin{array}{l}\text { THD } \\
(\%)\end{array}$ & $\begin{array}{c}\text { DC-link } \\
\text { capacitor } \\
\text { voltage - } \\
\Delta V_{D C}(V) \\
\end{array}$ \\
\hline 8 & 0 & 6.961 & 3.07 & 0.35 \\
\hline 8 & 0.1 & 4.99 & 2.81 & 0.27 \\
\hline 8 & 0.3 & 3.428 & 3.53 & 0.4 \\
\hline 8 & 0.5 & 2.477 & 4.54 & 0.55 \\
\hline 8 & 0.7 & 1.77 & 5.86 & 0.8 \\
\hline 8 & 0.9 & 1.414 & 7.07 & 1 \\
\hline 8 & 1.1 & 1.151 & 8.95 & 1.1 \\
\hline 8 & 1.3 & 0.973 & 9.82 & 1.15 \\
\hline 8 & 1.5 & 0.871 & 11.2 & 1.2 \\
\hline 8 & 1.7 & 0.781 & 13.47 & 1.3 \\
\hline 8 & 1.9 & 0.712 & 14.12 & 1.45 \\
\hline
\end{tabular}

\section{CONCLUSION}

The proposed FCS-MPC provides the excellent of grid-connected of PV system with the changes of injected power into grid, the low THD of grid current and the good DC-link capacitor voltage balance. Using the proposed FCS-MPC can achieve flexible to choose the switching frequency for the three-level T-Type NPC to enhance the efficiency of system while still guaranteeing about the problems concerned with the power quality as: DC-link capacitor voltage balance and THD of grid current. The proposed FCS-MPC only uses 27 switching states to calculate the cost function, considerably reduces the computation amount to enhance the efficiency of the proposed FCS-MPC. In addition, the proposed FCS-MPC is simple and easy to control in comparison with the traditional PWM for the control of DC-link capacitor voltage balance with the constant switching frequency [3].

\section{Giải thuật finite control set model predictive control để cân bằng điện áp tụ DC-link cho nghịch lưu T-Type NPC của hệ thống năng lượng mặt trời kết nối lưới}

- Phan Quốc Dũng

- Nguyễn Đình Tuyên

- Nguyễn Minh Nhật

Trường Đại học Bách Khoa, ĐHQG-HCM, Việt Nam

TÓM TÁT:

Bài báo này đề xuất giải thuật điều khiển Control (FCS-MPC) có bù trễ cho nghịch lưu dụ báo Finite control set Model Predictive 3 pha 3 bậc T-Type NPC (T-Type NPC) của 
hệ thống năng lượng mặt trời kết nối lưới. FCS-MPC được đề xuất cho điều khiển nhiều đối tượng: điều khiển bám dòng điện, cân bằng điện áp tụ $D C$-link, giảm tần số đóng cắt để qua đó đảm bảo các vấn đề chất lượng điện năng và hiệu suất của hệ thống năng lượng mặt trời kết nối lưới. Hàm mục tiêu của FCS-MPC sử dụng 27 trạng thái đóng cắt khác nhau của T-Type NPC, trạng thái đóng

Từ khóa: Finite control set Model predictive control, giảm tần số đóng cắt, cân bằng điện áp tụ DC-link, nghịch lưu T-Type NPC, hệ thống năng lượng mặt trời. cắt tối ưu được chọn trong mỗi thời gian lấy mẫu là trạng thái mà ở đó hàm mục tiêu có giá trị bé nhất. Giải thuật FCS-MPC được đề xuất là có bù trễ với hai thời khoảng dự báo tại thời điểm k+2 để qua đó giúp giảm méo dạng sóng hài của dòng điện lên lưới. FCSMPC được đề xuất sử dụng phần mềm Matlab/Simulink để kiểm chứng.

\section{REFERENCES}

[1]. Schweizer, M.; Kolar, J.W., Design and Implementation of a Highly Effiient ThreeLevel T-Type Converter for Low-Voltage Applications, Power Electronics, IEEE Transactions on, pp. 899 - 907, June 2012.

[2]. June-Seok Lee; Kyo-Beum Lee, New Modulation Techniques for a Leakage Current Reduction and a Neutral-Point Voltage Balance in Transformerless Photovoltaic Systems Using a Three-Level Inverter, Power Electronics, IEEE Transactions on, pp. 1720 - 1732, June 2013.

[3]. Ui-Min Choi; Blaabjerg, F.; Kyo-Beum Lee, Method to Minimize the Low-Frequency Neutral-Point Voltage Oscillations with Time-Offset Injection for Neutral-PointClamped Inverters, Industry Applications, IEEE Transactions on, pp. 1678 - 1691, August 2014.

[4]. June-Seok Lee; Kyo-Beum Lee, A CarrierBased PWM Method for Neutral-Point Ripple Reduction of a 3-Level Inverter, Energy Conversion Congress and Exposition (ECCE), IEEE Transactions on, pp. 2095 2100, Sept. 2014.

[5]. Hyun-Hee Lee, Ui-Min Choi, Kyo-Beum Lee, Neutral-Point Voltage Control for Grid 
Review of Its Applications in Power Electronics, Industrial Electronics Magazine, IEEE Transactions on, pp. 16 - 31, March 2014.

[10].Almaktoof, A.M.; Raji, A.K.; Kahn, M.T.E., Finite-Set Model Predictive Control and DClink Capacitor Voltages Balancing for ThreeLevel NPC Inverters, Power Electronics and Motion Control Conference and Exposition (PEMC), IEEE Transactions on, pp. 224 229, Sept. 2014.

[11].Jiefeng Hu; Jianguo Zhu; Dorrell,D.G., Model Predictive Control of Grid-Connected Inverters for PV Systems With Flexible Power Regulation and Switching Frequency Reduction, Energy Conversion Congress and Exposition (ECCE), IEEE Transactions on, pp. 540 - 546, Sept. 2013.

[12].Karamanakos,P.; Geyer, T.; Oikonomou,N.; Kieferndorf,F.D.; Manias,S., Direct Model Predictive Control: A Review of Strategies That Achieve Long Prediction Intervals for Power Electronics, Industrial Electronics Magazine, IEEE Transactions on, pp. 32 43, March 2014.

[13].Scoltock, J.; Geyer, T.; Madawala,U.K., A Model Predictive Direct Current Control Strategy with Predictive References for MV Grid-Connected Converters with LCLFilters, Power Electronics, IEEE Transactions on, pp. 1, December 2014.
[14].Calle-Prado,A.; Alepuz,S.; Bordonau, J.; Nicolas-Apruzzese, J. ; Cortes, P.; Rodriguez, J., Model Predictive Current Control of GridConnected Neutral-Point Clamped Converters to Meet Low Voltage Ride-Through Requirements, Industrial Electronics, IEEE Transactions on, pp. 1503 - 1514, October 2014.

[15].Uddin, Muslem ; Mekhilef, Saad; Nakaoka, Mutsuo; Rivera, Marco, Model Predictive Control of Induction Motor with Delay Time Compensation: An Experimental Assessment, Applied Power Electronics Conference and Exposition (APEC), IEEE Transactions on, pp. 543 - 548, March 2015.

[16]. Remus Teodorescu, Marco Liserre and Pedro Rodríguez, Grid converters for photovoltaic and wind power systems, IEEE press \& John Wiley \& Sons, 2011.

[17].Jose Rodriguez; Patricio Cortes, Predictive control of power converters and electrical drivers, IEEE press and John Wiley \& Sons Ltd, 2012.

[18].Cortes, P.; Kouro, S.; La Rocca, B.; Vargas, R.; Rodriguez, J.; Leon, J.I.; Vazquez, S.; Franquelo, L.G., Guidelines for Weighting Factors Design in Model Predictive Control of Power Converters and Drives, Industrial Technology, IEEE International Conference on , pp. 1 - 7, Feb. 2009. 